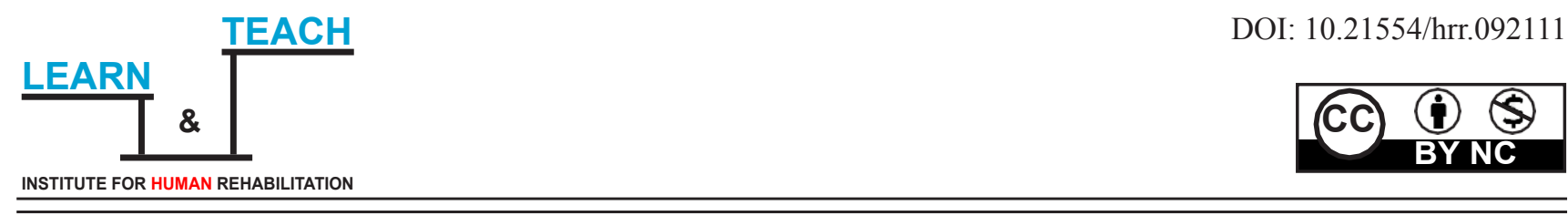

\title{
HUMAN RESOURCES MANAGEMENT DEVELOPMENT IN MICRO AND SMALL ENTERPRISES
}

Original scientific paper

\author{
Theranda Beqiri ${ }^{1}$, Brikend Aziri' \\ ${ }^{1}$ Faculty of Business, Department of Business Management, University ''Haxhi Zeka “, Pejë, Kosovo \\ ${ }^{2}$ Faculty of Economics, "University of Tetovo”, Tetova, Republic of North Macedonia
}

Received: $2021 / 7 / 23$

Accepted: 2021/9/24

\begin{abstract}
The HRM development takes on particular importance as it is considered to be an organizational function that promotes and creates space for creativity, innovation, speed, efficiency and effectiveness, thus transforming the workforce into a precious asset to the organization. In this research we investigate to what extent parts of modern HRM policies are mostly implemented in Micro and Small enterprises in Kosovo and how do they impact efficiency of the businesses and their workers, we have developed and implemented some questionnaires related to the important variables of this issue. Businesses should be able to provide competitive advantages in the market, successfully cope with the rapid advancement of technology, the effects of globalization, and the need to have an effective and efficient workforce to better fulfil their economic objectives. The HRM has its role in lifelong learning and development of employees, employee relations with co-workers and management, human relations, as well as motivation of employees. The development of HR practices has an impact not only on the economic development of an organization but also on the creation of positive effects on a country's economic and social development. This paper has basically descriptive and analytical research. The overall conclusion of the paper is that the efficient management of human resources has an impact on the development of the private business sector, and is positively related with increases in the efficiency of the employees and the firm, therefore the need for human resources management in private businesses is necessary and essential. Keywords: Human Resources, Microbusiness, Small business, Efficiency, Performance
\end{abstract}

\section{INTRODUCTION}

Human Resource Management is an important part of the management process function. The selection, training and evaluation of the workforce is an important and strategic tool that helps create an organization's sustainable competitive advantage and adds value to it. There is quite a research and organizations that are considering SMEs as the main generator of economic development but some factors that should not be overlooked such as attracting, motivating, developing and retaining long-term employees have been recognized as important challenges that are encountered by SMEs.

Development of Human Resources Management has grown in Kosovo as the role of human resources and their development is growing as well in today's business world. SMEs in Kosovo are divided by the number of workers Micro Enterprises - 1 to 9 employees, Small enterprise - 10 to 49 employees, Medium enterprise - 50 to 249 employees, large enterprise - over 250 employees. The development of small and medium-sized enterprises (SMEs) is the first goal of any modern economy. What distinguishes SMEs are employees, as their relationship with customers, how they solve problem situations, the speed of their responses to customers, motivation, ability to learn, etc. Employees are given an important role in organizations that aspire to be different from the competition.

\section{Correspondence to:}

Theranda Beqiri, Faculty of Business, Department of Business Management, University ''Haxhi Zeka“, Pejë, Kosovo

Brikend Aziri, Faculty of Economics, "University of Tetovo", Tetova, Republic of North Macedonia

E-mail: theranda.beqiri@unhz.eu; brikend.aziri@unite.edu.mk 
Human resource management has a more important role in the planning and realization of SME's objectives than in the previous period Drucker (2012) states that the entrepreneur is looking for change, responds to it and seizes opportunities. Invention is a unique tool for an entrepreneur to convert one resource into another through an effective venture. Ramsay, Scholarios, and Harley (2000) highlight the fact that the opportunities and benefits offered through HRM practices make employees have a better perception of meeting their needs.

The transition economy in Kosovo requires maximum efforts from central government and entrepreneurs to succeed in addressing local and international market challenges It is thought that the role of HRM is not sufficiently valued for its potential in organizational success, but rather seen as an administrative rather than managerial role. In many large companies, although there is an awareness among Kosovar entrepreneurs of having a team of highly qualified employees is a key component to be successful. Nevertheless, the role and importance of setting up an HRM department is still not understood in some cases as well as applying standardized practices of human resources management to create a productive, motivated and successful workforce.

\section{LITERATURE REVIEW}

The HRM function consists of a set of employee management policies and practices that are particularly important for enhancing organizational performance. Effectively and effectively developing these policies and practices brings benefits to the organization by improving the quality and productivity of services as well as enhancing employee benefits. According to Gubbins and Garavan (2016) the formulation, implementation and evaluation of appropriate HRM practices greatly impact the success of the organization. Whereas, Katou (2012) argues that if HRM policies and practices are well formulated they influence managers 'and employees' perceptions and attitudes toward work. Organizational best practices describe how all the ingredients should be deployed and managed. Included are all the key human factors, such as motivation, incentives, skills, experience, education, training, loyalty, and commitment (Axson, 2010). Shafeek (2016) in his research found that there is a positive relationship between best practices and SMEs but they also lead to success of the company. Although, Parilla (2013) suggested that 'Since the micro businesses employ their family members, they do not strictly implement rules on salaries and benefits while for small businesses, they have more formal structure and they employ not only their family members they are more strict in practicing salaries and benefits' rules and regulations. The function of HRM department is essential to achieving a secure, stable and sustainable business for employees. But the way the department works and the use of models and techniques is different from business to business.
Therefore, each business has adopted its own management model that fulfils its needs and requirements, in line with the objectives and employee satisfaction. The ways of managing human resources are many and their study constantly creates new practices for their management. However, this creates an ambiguous situation regarding human resource management practices and does not appear to be reached by a common denominator as determinants of that set of practices that have the greatest impact on human resource management. There is no single agreed, or fixed, list of HR practices or systems of practices that are used to define or measure human resource management. The advent of network organizations, the growth of knowledge workers, and the development of non-standard employment contracts have all had major implications for the way people are managed in contemporary organizations, meaning that the very object of study that is at the heart of HRM, is itself subject to change (Boon, Paauwe, Boselie, \& Den Hartog, 2009). Wright, et al. (2005) studied Strategic Human Resources in more generalized context and found out that differences in culture and environment in which business work can set boundaries in results of empirical work. A strategic approach to human resources also involves investing in human resources, since a significant share of human capital is determined by the knowledge and skills that individuals acquire. Knowledge and skills greatly influence the performance of employees, so education is a very important factor in the economic development of a country and individual companies and leads to the achievement of economic and social goals. Whilst Kaufman (2010) suggested that not all theories of HRM are applicable to various businesses and firms and, that some theories are partially intended for the larger organizations and are applicable for those and other theories are partially applicable to smaller firms, which also depends on the social and cultural factors of the organization can have an impact on the procedures of HRM. Kinnie et al. (2005) found that most important relationship with the commitment of employees to the organization is connected with fairness, rewards as well as work life balance not having to work overtime and have absence to home related duties. A distinctive capability reflects a level of performance a company can achieve that is a function of a company's unique skills or abilities in an area. Examples of unique capabilities are those that result from internal innovation, proprietary knowledge, or some other driver of competitive advantage (Axson, 2010).

\section{Human Resources Management Models}

Most researchers construct a list of practices but there is no agreement on what or which practices to include. While core practices associated with recruitment and selection, training and development, and performance management are nearly always included, others like job design and involvement are much more 
sporadic Boxall, Purcell, and Wright (2007). Different practices show that different models and practices of HRM, which differ taking into account different organisations but they correspond with conceptual forms of HRM. World practice has shown that there are many HRM models and practices that vary in form in different organizations but which correspond to the conceptual aspects of HRM. The existence of theories of HRM development and the influence of external and internal environmental factors, as well as the increase of competitiveness, have had their impact on the formulation and development of contemporary HRM concept, practices and policies.

In summary, the most common HRM models are:

-The Boselie Paauwe, and Richardson (2003) model of the relationship between HRM activities, HR outcomes and organizational performance focuses on three links: HR management activities, their relation to HR results, as well as their relation to HR results and organizational performance. According to this model, the performance of public enterprises is linked to the underlying mechanisms: a) Coercive mechanisms stemming from political influence and legitimacy problems; b) Imitation mechanisms resulting from standard responses to uncertainty; c) Normative mechanisms, which are associated with professionalism.

-HRM Matching Model - This model has been proposed by Devanna, Fombrun, and Tichy, (1981). These authors emphasize that HRM systems and organizational structure must be managed in a way that is consistent with the organization's strategy (Armstrong, 2006). According to them 'the key management task is to align the formal structure with the HR systems in such a way that they drive the fulfilment of the organization's strategic objectives'. This group of authors were the first to take steps towards developing the strategic management concept of HR.

1. Selection - matching available human resources to jobs;

2. Appraisal-performance management;

3. Rewards - "the reward system is one of the most under-utilized and mishandled.

Managerial tools for driving organizational performance'; it must reward short as well as longterm achievements, bearing in mind that 'business must perform in the present to succeed in the future'; 4. Development - developing high quality employees. -Harvard Model for HRM - this model was developed by Beer et al. (1984) and is based on the principle that 'HRM encompasses all management decisions and actions that affect the type of relationship between the organization and its employees'. They believed that increasing pressure from the external market requires more strategic HR management, and that it was necessary for HR management to be in the long run considering employees as assets rather than just variable costs.
According to them HRM is based on two main characteristics:

a) Line managers assume more responsibility to ensure compliance of HR policies with competitive strategy;

b) HRM aims at defining policies that guide the way HRM activities are developed and implemented so that they mutually reinforce each other. This model was reviewed from the same authors after thirty years where they added also the effects of change management during the years saying that "firm must change with regard to employees and other stakeholder and that organizations might best go about the process of change itself "(Beer, Boselie, \& Brewster, 2015).

According to Agyepong et al. (2010), the organizational situational factors of the Harvard model: workforce characteristics; the business strategy and conditions; management philosophy; labour markets; unions; task technology and laws and social values have their impact in further development of HRM. Armstrong (2006) says that "The Harvard model has exerted considerable influence over the theory and practice of HRM, particularly in its emphasis on the fact that HRM is the concern of management in general rather than the personnel function in particular".

-HRM Contextual Model - This model emphasizes the importance of environmental factors on HRM including variables such as: the impact of the social, institutional and political aspects that are underestimated in other models. This model's approach is broad and integrates the human resources management system into the environment in which it is developed. According to Martin-Alcazar et al (2005) 'context is conditioned and accustomed by the human resources management strategy'.

-Operational HRM linkage with Business strategy model was developed by Katou (2008) whereas, according to this model the business strategy is closely linked to three basic factors: costs, quality and innovation. These factors qualify as the basis on which a business chooses the form of action that is constantly seeking to increase efficiency, efficiency, job satisfaction, innovation, development and quality. With all this models we have developed a model that might include some of the practices of HRM that are more applicable for micro and small businesses.

\section{RESEARCH METHODOLOGY AND RESULTS}

The purpose of this paper is to increase understanding of human resource management practices within small and medium-sized enterprises. To develop a research model we have gathered data from micro and small business, from which we have respondents of 39 microbusinesses and 71 small businesses. Through the questionnaire we tried to obtain data on HRM practices that are used most commonly applied in Small businesses and microbusinesses. We have used descriptive data analysis with Crostabulation and Chi Square test, for reliability of the data we have used Cronbach alpha and for testing the hypothesis we have used multiple regression analysis. 
In literature review we have explored some of the contemporary models of HRM and in the research questions we have incorporated some of the practices that we derived from this models, taking into account also the strategic plans of HRM that are according to their business strategy as well as other issues as: planning of HRM, work design, innovation creativity, programs policies and implementation of the HRM policies that are essential part of HRM as contracts for employees, health security so on. For example Innovation is considered as part of business strategies in most models. Efficiency is also part business strategies as well as creativity. Know that are constant changes in business environment and small and microenterprises are more flexible in decision making concerning the needs of the market that they are targeting, therefore they also should they align their HRM strategies in line with the ones of the firm. And policies that are requested by law with other issues as motivation of employees.

Human resources management has four basic activities, namely:

- Staffing (employment planning, recruitment, selection and orientation, performance appraisal, rewards)

-HR programs and practices - activities implemented by HR programs and policies. They include ensuring HR, learning and development, performance management and reward management, employee administration and the regulation of employment relationships.

-HR strategies in line Business Strategies cost/ investment, innovation efficiency, creativity. Do they include ensuring HR, learning and career development, and reward management?

HR practices - activities implemented by HR programs and policies. Employee administration and the regulation of employment relationships (contracts, health insurance)?

Table 1. Crosstab Micro Businesses, Small Business
The main Hypothesis is

$\mathbf{H}_{0}: \overline{\mathrm{a}}=0$ Does implementation of HRM practices increases efficiency of employees and firm performance?

Sub Hypothesis 1: Does implementation of HRM staffing practices increases efficiency of Efficiency of the Business?

Sub Hypothesis 2: Do HRM strategies increase Efficiency of the Business?

Sub Hypothesis 3: Do HR practices that are obliged by Labour Law increase efficiency of the employees?

Some of the main research questions are:

Research Question 1 - Do Micro and Small enterprises apply policies regarding staffing as employment planning, recruitment selection and orientations, job descriptions?

Research Questions 2 - Are the HRM strategies in line with Business strategies which increases efficiency of small businesses?

Research Question 3 - Do they reward innovation and creativity of employees, as well as efficiency, do they implement development of employees?

Research Question 4 - Do the firms have work design and do they conduct work analysis?

Research Question 5 - Are the HR practices implemented as employee administration and the regulation of employment relationships?

Research Question 6 - Does your firm pay health insurance for the employees?

\section{Descriptive Results}

We start with descriptive data where we can see from the table1 of cross tabulation below that we have responses for microbusinesses of $64.1 \%$ from males and $35.9 \%$ from females from total 39 microbusinesses and for small business we have a $63.4 \%$ female respondents compared with $36.6 \%$ males from total of 71 small businesses.

\begin{tabular}{|c|c|c|c|c|c|}
\hline & & & \multicolumn{2}{|c|}{ Gender } & \multirow[b]{2}{*}{ Total } \\
\hline & & & Female & Male & \\
\hline \multirow{8}{*}{ SME } & \multirow{4}{*}{ Microbusiness } & Count & 14 & 25 & 39 \\
\hline & & $\%$ within SME & $35.9 \%$ & $64.1 \%$ & $100.0 \%$ \\
\hline & & $\%$ within gender & $23.7 \%$ & $49.0 \%$ & $35.5 \%$ \\
\hline & & $\%$ of Total & $12.7 \%$ & $22.7 \%$ & $35.5 \%$ \\
\hline & \multirow{4}{*}{ Small Business } & Count & 45 & 26 & 71 \\
\hline & & $\%$ within SME & $63.4 \%$ & $36.6 \%$ & $100.0 \%$ \\
\hline & & $\%$ within gender & $76.3 \%$ & $51.0 \%$ & $64.5 \%$ \\
\hline & & $\%$ of Total & $40.9 \%$ & $23.6 \%$ & $64.5 \%$ \\
\hline \multirow{4}{*}{ Total } & & Count & 59 & 51 & 110 \\
\hline & & $\%$ within SME & $53.6 \%$ & $46.4 \%$ & $100.0 \%$ \\
\hline & & $\%$ within gender & $100.0 \%$ & $100.0 \%$ & $100.0 \%$ \\
\hline & & $\%$ of Total & $53.6 \%$ & $46.4 \%$ & $100.0 \%$ \\
\hline
\end{tabular}

From Table 2 below we can see that the significance Asymp significance ( 2 sided) .006 is lower .05 which tests relationships between variables in the respondents or if they are truly independent therefore we can say that the results from microbusinesses and small businesses are independent from each other. 
Table 2. Chi-Square Tests

\begin{tabular}{|c|c|c|c|c|c|}
\hline & Value & df & $\begin{array}{c}\text { Asymp. Sig. } \\
\text { (2-sided) }\end{array}$ & $\begin{array}{l}\text { Exact Sig. } \\
\text { (2-sided) }\end{array}$ & $\begin{array}{c}\text { Exact Sig. } \\
\text { (1-sided) }\end{array}$ \\
\hline Pearson Chi-Square & $7.646^{\mathrm{a}}$ & 1 & .006 & & \\
\hline Continuity Correction ${ }^{\mathrm{b}}$ & 6.580 & 1 & .010 & & \\
\hline Likelihood Ratio & 7.710 & 1 & .005 & & \\
\hline Fisher's Exact Test & & & & .009 & .005 \\
\hline Linear-by-Linear Association & 7.576 & 1 & .006 & & \\
\hline $\mathrm{N}$ of Valid Cases & 110 & & & & \\
\hline
\end{tabular}

a. 0 cells $(0.0 \%)$ have expected count less than 5 . The minimum expected count is 18.08 .

b. Computed only for a $2 \times 2$ table

\section{Research Results and Interpretation}

In this research we have used Cronbach's alpha tests to see if multiple-question Likert scale surveys are reliable and are they accurately measuring the variables that we are interested on. These questions measure latent variables - hidden or unobservable variables measures reliability, or internal consistency. "Reliability" is how well a test measures what it should.' Cronbach's alpha is a test reliability technique that requires only a single test administration to provide a unique estimate of the reliability for a given test. Cronbach's alpha is the average value of the reliability coefficients one would obtained for all possible combinations of items when split into two half-test' (Gliem \& Gliem, 2003).

Cronbach's alpha formula

$$
\alpha=\frac{N \cdot \bar{c}}{\bar{v}+(N-1) \cdot \bar{c}}
$$

Where: $\mathrm{N}=$ the number of items, $\overline{\mathrm{c}}=$ average covariance between item-pairs, $\overline{\mathrm{v}}=$ average variance.
From the Cronbach alpha results we can find reliability statistics, where from the table 3 below we can see that results Cronbach alpha $=.813$ are very satisfactory which shows the goodness of fit of the variables chosen for this research. From the 18 questions that we had in the first phase of this research only 11 research questions showed reliability or internal consistency after Cronbach alpha test results. Therefore, we continued with the relevant and satisfactory research questions.

\section{Table 3. Reliability Statistics}

\begin{tabular}{ccc}
\hline $\begin{array}{c}\text { Cronbach's } \\
\text { Alpha }\end{array}$ & $\begin{array}{c}\text { Cronbach's Alpha Based } \\
\text { on Standardized Items }\end{array}$ & N of Items \\
\hline .804 & .813 & 11 \\
\hline
\end{tabular}

From the table 4 below item statistics we can see that from 11 items none of them have the Cronbach's Alpha if Item Deleted higher than reliability statistics, therefore we can say that the data fit the model.

\section{Table 4. Item-Total Statistics -Reliability Statistics}

\begin{tabular}{lc} 
& Cronbach's Alpha if Item Deleted \\
\hline Development OF HRM-Staffing $(,)$, & .786 \\
Planning of HRM employment planning, & .786 \\
Recruitment, selection and orientation & .783 \\
HRM strategies Business Strategies & .780 \\
Formal policies of career development and advancement & .784 \\
HRM efficiency & .776 \\
Innovation & .771 \\
Creativity & .811 \\
Contract & .803 \\
Insurance & .781 \\
Motivation & .785 \\
\hline
\end{tabular}

\section{Regression Analysis Results and Interpretation}

Since the data and the results from Cronbach alpha are reliable we continue to prove and analyse our research questions and hypotheses that are related to HRM.To analyse and approve the main Hypothesis Does implementation of HRM practices increases efficiency of employees and firm performance?
As explained we have developed three sub hypothesis: Sub Hypotheses 1 - Development of HRM in Micro and small businesses by interpreting the results of multiple regression analysis.

$Y "=\bar{a}+\beta 1$ Planning of HRM $+\beta 2$ Recruitmentselection $+\beta 3$ Jobdescription $+\varepsilon$

Where: $Y "=\bar{a}$ Predicted variable and $Y$ (the dependent variable- Development of HRM staffing practices). 
Independent variables are; X1 = Planning of HRM employment planning, $\mathrm{X} 2=$ Recruitment, selection and orientation, $\mathrm{X} 3=\mathrm{Job}$ description,

$\mathrm{R}$ square $\mathrm{R}$ is used to find out how suitable are the independent variables to predict the dependent variable, $\mathrm{R}$ square value is less inflated when the number of independent variables is greater. From the table 5 below we can see that $\mathrm{R}$ square is .329 and adjusted Rsquare .310 although not high it explains the development of HRM procedures for staffing for 31 percent and since the significance is High 0.00 we can say that our data explain research question. From the Table5 we can see that which independent variables explain the dependent variable. We use standardized Beta coefficients measured by standard deviation:

Planning of HRM has significant value $p=.0$ and $<.05$, while its coefficient is .274 and this represents that for every unit increase in better planning development of
HRM staffing in Micro and small businesses increases for 27.4 percentage points, if we consider that all the other variables are constant. Recruitment, selection and orientation has significant value $\mathrm{p}=.0$ and $<.01$, while its coefficient is .274 and this represents that for every unit increase in better recruitment and selection procedures of HRM staffing in Micro and small businesses increases for 37.5.4 percentage points. While Job description although has a significant value $\mathrm{p}=.0$ and $<.45$ gives us a negative results, decrease -12 percentage points which might be due to lack of adequate forms and clarifications on job descriptions in micro and small businesses. We can say that we accept the results of this sub hypothesis and that adequate planning of the staffing and recruitment practices have a positive relationship with increased Human resources development and increased efficiency in micro and small businesses.

Table 5. Regression results - Development OF HRM-Staffing

\begin{tabular}{lcccccc}
\hline \multicolumn{1}{c}{ Model Summary } & $\begin{array}{c}\text { R } \\
\text { Square }\end{array}$ & $\begin{array}{c}\text { Adjusted } \\
\text { R Square }\end{array}$ & B & $\begin{array}{c}\text { Std. } \\
\text { Error }\end{array}$ & Sig. \\
\hline & .329 & .310 & & & & \\
Constant & & & 1.182 & .309 & 3.820 & .000 \\
Planning of HRM Employment planning, & & & .274 & .079 & 3.463 & .001 \\
Recruitment, selection and orientation & & & .375 & .087 & 4.334 & .000 \\
Job description & & & -.126 & .062 & -2.026 & .045 \\
\hline
\end{tabular}

We continue with the second part of research question and sub hypothesis regarding HRM efficiency.

Sub Hypotheses 2 - Do HRM strategies increase Efficiency of the Business? We developed this hypothesis with the research questions related to innovation creativity career development and policies of work design which includes, work plan of employees.

The second hypothesis is HRM efficiency in Micro and small Businesses the results of multiple regression analysis

$\mathrm{Y}$ " $=\overline{\mathrm{a}}+\beta$ career development $+\beta$ Innovation $+\beta$ Creativity $+\beta$ Work design $+\varepsilon$

Where: $Y^{\prime \prime}=\bar{a}$ Predicted variable and $\mathrm{Y}$ (the dependent variable- HRM efficiency ().

Independent variables are; X1 = career, development and advancement, $\mathrm{X} 2=$ Innovation $\mathrm{X} 3=$ Creativity $\mathrm{X} 4=$ Work design
From the Table 6 below we can see that the model is significant Policies of Career development and advancement has significant value $p=.1$ and $<.05$, while its coefficient is .289 and this represents that for every unit increase in career development and chance of advancement in Micro and small businesses efficiency increases for almost 30 percentage points, if we consider that all the other variables are constant. Innovation have a significant value $\mathrm{p}=.0$ and $<.01$, while its coefficient is .44 2 and this represents that for every unit increase in innovation in Micro and Small businesses efficiency increases for 45 percentage points. Creativity does not have significant results, whilst work design as work plan and so on is important and increases HRM efficiency for $16 \%$ points. Also in the second sub hypothesis from the results we can conclude that there is a significant impact of HRM practices in increased efficiency of the firms.

Table 6. Regression results - HRM-Efficiency

\begin{tabular}{|c|c|c|c|c|c|c|}
\hline Model Summary & R Square & $\begin{array}{l}\text { Adjusted } \\
\text { R Square }\end{array}$ & B & Std. Error & $\mathbf{t}$ & Sig. \\
\hline & .447 & .420 & & & & \\
\hline Constant & & & -.403 & .333 & -1.209 & .229 \\
\hline $\begin{array}{l}\text { Formal policies of career } \\
\text { development and advancement }\end{array}$ & & & .289 & .087 & 3.314 & .001 \\
\hline Innovation & & & .442 & .093 & 4.753 & .000 \\
\hline Creativity & & & .067 & .076 & .891 & .375 \\
\hline Work design & & & .167 & .069 & 2.407 & .018 \\
\hline
\end{tabular}


Sub Hypotheses 3 is related with policies and practices that are required by Labour law, (Law No.03/L -212) we continue with third research question and hypothesis regarding HRM implementation in Micro and Small businesses the results of multiple regression analysis.

$\mathrm{Y}^{\prime \prime}=\overline{\mathrm{a}}+\beta$ employment contract $\mathrm{a}+\beta$ Health insurance $+\beta$ wages $+\varepsilon$

Where: $Y "=\bar{a}$ Predicted variable and $\mathrm{Y}$ (the dependent variable- HRM Policies by law

Independent variables are; X1 = employment contract, $\mathrm{X} 2=$ health insurance $\mathrm{X} 3=$ wages

From the table 7 below we can see that the model is significant work contracts has significant value $\mathrm{p}=.0$ and $<.05$, while its coefficient is .96 and this represents that for every unit increase in employment contract in Micro and small businesses practices of HRM increases for more than 90 percentage points, if we consider that all the other variables are constant. Health insurance is not significant and wages have a significant value $p=.0$ and $<.031$, while its coefficient is .057 and this represents that for every unit increase in wages in Micro and small businesses efficiency increases for 5 percentage points. We can conclude with the third sub hypothesis that the most important issue that concerns increased efficiency of employees are employment contract, having in mind that the Kosovo is still in transition and unemployment is high and there is a informal economy this result might be expected .

Table 7. Regression results Implementations of HRM policies

\begin{tabular}{lcccccc}
\hline Model Summary & R Square & $\begin{array}{c}\text { Adjusted } \\
\text { R Square }\end{array}$ & B & Std. Error & t & Sig. \\
\hline & .931 & .929 & & & & \\
Constant & & .236 & .109 & 2.161 & .033 \\
Employment Contract & & .961 & .027 & 35.655 & .000 \\
Health insurance & & -.033 & .035 & -.936 & .351 \\
Wages & & .057 & .026 & 2.190 & .031 \\
\hline
\end{tabular}

\section{DISCUSSIONS}

In this research we have explored the level of implementation of Human Resources Management policies and practices in Micro and small businesses. The importance of Human Resources Management practices in this type of businesses is larger since they usually do not have a department of Human resources, and managers or the owners of the businesses are usually also the human resources managers which is especially common at the micro businesses. Although, at the Microbusinesses the managers and employees have closer relationship since they work together in day to day business, therefore we may say that they do not have formal procedures of performance evaluation, and job descriptions but when it comes to staffing as recruitment and selection, and planning of the new staff they are more equipped to employee more qualified workers. When it comes to another very important function of Human resources management, which is to be recognized as an important part of the business and to have its place in line with business strategy we can say that although Kosovo is still in transition, the reward for innovation exists in Micro and Small businesses as well as plans for career development as trainings are conducted, which are very important for both employees and businesses to have better success and increase efficiency of the work and businesses. From the research we did not have a significant results for creativity and motivation of the employees this might be since small businesses and micro businesses do not have high wages, and they are in constant competition with start-ups and new businesses. When we explored the practices that are obliged by the labour law we found that the employees contracts are the most important in private businesses, this is expected taking into account high level of informal economy in Kosovo. Health insurance is particularly important after the Pandemic Covid -19 but nevertheless, in Kosovo although it exists in the Labour Law it is not implemented yet as the obligatory for the firm owners to provide to their employees.

\section{CONCLUSIONS}

From this research we can conclude that HRM practices in Micro and small businesses are in the first phase even though some of very important parts of Human resources development are implemented. Kotey and Sheridan (2004) studied changes of HRM from informal to formal procedures with the growth of the firms in size, and found as the number of employees increase the more hierarchical administrative are required. There is a little research on HRM implementation in Micro and small businesses with formal procedures, therefore this study has its importance regarding HRM development. From the findings of this study we can conclude that some parts of HRM as employee contracts administration, recruitment and selection procedures, and reward for innovation are implemented in Kosovo. Business Efficiency is also part business strategies and we can say that it is in positive relationship with the HRM efficiency taking into account the changes in business environment and flexibility of decision making in Micro and small businesses. 
Another issue that we may conclude from the results is that in micro and small businesses part of the staff are family members and from our results, the recruitment and selection procedures and career development of employees are implemented, therefore we may say that business owners and managers even though might not have resources have understood the importance of having qualified employees and keeping them in their firms.

\section{REFERENCES}

Agyepong, S.A., Fugar, F.D., \& Tuuli, M.M. (2010). The applicability of the Harvard and Warwick models in the development of human resource management policies of large construction companies in Ghana. Available at: https://scholar.google.com/citations?view op=view citation\&hl=en\&user=FM6AtvkAAAAJ\&citation_for view $=$ FM6AtvkAAAAJ:Tyk-4Ss8FVUC

Armstrong, M. (2006). A handbook of human resource management practice: Kogan Page Publishers.

Axson, D.A. (2010). Best practices in planning and performance management: Radically rethinking management for a volatile world: John Wiley \& Sons.

Beer, M., Boselie, P., \& Brewster, C. (2015). Back to the future: Implications for the field of HRM of the multistakeholder perspective proposed 30 years ago. Human Resource Management, 54(3), 427-438.

Boon, C., Paauwe, J., Boselie, P., \& Den Hartog, D. (2009). Institutional pressures and HRM: developing institutional fit. Personnel Review.

Boselie, P., Paauwe, J., \& Richardson, R. (2003). Human resource management, institutionalization and organizational performance: a comparison of hospitals, hotels and local government. The International Journal of Human Resource Management, 14(8), 1407-1429.

Boxall, P., Purcell, J., \& Wright, P. M. (2007). Human resource management. In The Oxford handbook of human resource management.
Devanna, M. A., Fombrun, C., \& Tichy, N. (1981). Human resources management: A strategic perspective. Organizational Dynamics, 9(3), 51-67.

Drucker, P. (2012). Managing in the next society: Routledge.

Gliem, J.A., \& Gliem, R.R. (2003). Calculating, interpreting, and reporting Cronbach's alpha reliability coefficient for Likerttype scales. Midwest Research-to-Practice Conference in Adult, Continuing, and Community Education.

Gubbins, C., \& Garavan, T. (2016). Social capital effects on the career and development outcomes of HR professionals. Human Resource Management, 55(2), 241-260.

Katou, A.A. (2008). Measuring the impact of HRM on organizational performance. Journal of Industrial Engineering and Management (JIEM), 1(2), 119-142.

Katou, A.A. (2012). Investigating reverse causality between human resource management policies and organizational performance in small firms. Management Research Review. 35 (2), 134-156. https://doi. org/10.1108/01409171211195161

Kaufman, B. E. (2010). The theoretical foundation of industrial relations and its implications for labor economics and human resource management. ILR Review, 64(1), 74-108.

Kotey, B., \& Sheridan, A. (2004). Changing HRM practices with firm growth. Journal of Small Business and Enterprise Development, 11(4):474-485, DOI:10.1108/14626000410567125

Parilla, E. S. (2013). Level of management practices of micro and small businesses in Ilocos Norte. International Journal of Academic Research in Business and Social Sciences, 3(7), 439.

Ramsay, H., Scholarios, D., \& Harley, B. (2000). Employees and high-performance work systems: Testing inside the black box. British Journal of industrial relations, 38(4), 501-531.

Shafeek, H. (2016). The impact of human resources management practices in SMEs. Annals of the Faculty of Engineering Hunedoara, 14(4), 91.

Wright, P. M., Gardner, T. M., Moynihan, L. M., \& Allen, M. R. (2005). The relationship between HR practices and firm performance: Examining causal order. Personnel psychology, 58(2), 409-446.

Labour law, Law No.03/L -212. Republic of Kosovo https://www. oakks.org/repository/docs/LAW_ON_LABOUR_878043. pdf accessed 10th ofMay2021 